\title{
RADIOGRAPHIC ASSESSMENT OF PULMONARY FLUID CLEARANCE IN HEALTHY NEONATAL FOALS
}

\author{
Orsolya Kutasi, Andras Horvath, Andrea Harnos, Otto Szenci
}

\begin{abstract}
We characterized the kinetics of postnatal equine lung using sequential thoracic radiography. The aim was to establish the earliest time when normal foals have clear, radiolucent lung fields, and to characterize the pattern of this clearance. Both right-to-left and left-to-right thoracic radiographs were acquired in lateral recumbency at peak inspiration within the first $30 \mathrm{~min}$ after birth and thereafter at $1,2,3,4,6,8,12,24,48$, and $72 \mathrm{~h}$. Radiographs were interpreted by three observers. The overall assessment of radiographic lung clearance was followed by the evaluation of individual lung quadrants to document changes in pulmonary radiographic patterns over time. We concluded that thoracic images in a healthy foal older than $4 \mathrm{~h}$ should be characterized by clear lungfields and that after this time distinctions between physiologic and pathologic conditions can be made. The ventral lung cleared first, presumably due to the greater flexibility of the thoracic wall in this anatomic region. Veterinary Radiology \& Ultrasound, Vol. 50, No. 6, 2009, pp 584-588.
\end{abstract}

Key words: clearance, neonatal foal, thoracic radiography.

\section{Introduction}

I MMEDIATELY AFTER BIRTH, the airways of foals are rapidly cleared of liquid to allow the onset of air breathing. This initiates a cascade of physiologic changes that enable the lung to adapt to gas exchange. Most studies about the adaptation period focus on liquid clearance because liquid retention in airways is a major cause of respiratory morbidity in newborn infants. ${ }^{1}$

The prevalence of pulmonary disease in hospitalized neonatal foals has been reported to be approximately $50 \%$, with a $39 \%$ survival to discharge. ${ }^{2}$ Early recognition of respiratory abnormalities during the postnatal period is of special importance for successful management of critically ill foals. ${ }^{3}$ In most foals, physical examination is not adequate for precise identification of the cause or severity of respiratory dysfunction, even when clinical signs are present. $^{4-7}$ Clinical signs have to be interpreted in conjunction with blood gas- and acid-base analysis, radiographic findings, and other laboratory values.

Thoracic radiographs of foals made immediately after birth are characterized by a pronounced interstitial-alveo-

From the Clinic for Large Animals, Ullo 2225 (Kutasi, Horvath, Szenci), and the Department of Biomathematics (Harnos), Budapest 1078, Hungary.

Radiographic follow-up of the postnatal clearance of foetal lung fluid (short communication). Annual Meeting of the French Equine Veterinary Association, 2006, Versailles.

Postnatal clearance of foetal lung fluid (short communication). The 25 th Symposium of the Veterinary Comparative Respiratory Society, 2007, Lafayette.

Address correspondence and reprint requests to Orsolya Kutasi, at the adove address. E-mail: kutasi.orsolya@aotk.szie.hu

Received July 18, 2008; accepted for publication June 8, 2009.

doi: $10.1111 /$ j.1740-8261.2009.01587.x lar opacity with blurring of small vessels. This opacity is the result of incomplete lung inflation, the presence of residual fluid in the small airways, and uptake of fetal alveolar fluid into the lung interstitium. ${ }^{7,8}$ Foals with respiratory disease may have a similar radiographic pattern, but it typically persists beyond the normal absorption time.

Pulmonary fluid production decreases over the last few days before natural delivery. ${ }^{9}$ Only a small fraction of pulmonary fluid is cleared from the airways and alveoli as the foal traverses the birth canal. ${ }^{10}$ After birth, pulmonary fluid moves rapidly through amiloride-sensitive $\mathrm{Na}^{+}$channels in the epithelium to the pulmonary interstitium, where it is cleared by pulmonary lymphatics and vessels. ${ }^{3,10-12}$ Although aquaporin channels provide the main route for osmotically driven water transport, alveolar fluid clearance in the neonate is not affected by aquaporin deletion. ${ }^{13}$ Colloid oncotic effects and Starling forces also do not play a key role in pulmonary fluid absorption in neonatal foals. $^{10,14}$ In healthy mature lambs, the transepithelial component of lung liquid clearance requires $2-3 \mathrm{~h}$ and drainage of fluid from the interstitium is complete by the 6th hour after birth. ${ }^{15}$

As normal pulmonary fluid can complicate interpretation of thoracic radiographs of neonates with pulmonary disease, it is important to know the kinetics of fluid removal, and also the earliest time at which normal-term foals have a normal lung pattern on thoracic radiographs. The purpose of this report was to characterize those criteria.

\section{Materials and Methods}

One hundred and seventy-six radiographs of eight newborn foals of different breeds (Hungarian Halfbreds and 
Hungarian Draughthorses) born in the years 2003 and 2004 were assessed by three independent reviewers who were unaware of the age and status of the foals. So that foals could be radiographed shortly after birth, mares about to give birth were evaluated every $2 \mathrm{~h}$ using a foaling monitoring system. ${ }^{*}$ After birth the heart rate, respiratory rate, and body temperature were measured, and auscultation over the heart and lung was performed. Arterial blood gas analysis was also performed within $15 \mathrm{~min}$ after birth and before each radiographic examination. Blood was collected anaerobically from the great metatarsal artery into heparinized $(1000 \mathrm{IU} / \mathrm{ml})$ plastic syringes. Blood samples were analyzed within $10 \mathrm{~min}$ after collection. The time after birth at which foals stood up for the first time, whether the foal was recumbent longer than $15 \mathrm{~min}$ on one side before radiography, and the time of first suckling were recorded. Venous blood was withdrawn from each foal within $24 \mathrm{~h}$ for quantification of complete blood cell count, and various serum electrolytes, glucose, protein, and various enzymes.

Right-to-left and left-to-right lateral thoracic radiographs were acquired within the first $30 \mathrm{~min}$ after birth and repeated thereafter at 1, 2, 3, 4, 6, 8, 12, 24, 48, and $72 \mathrm{~h}$. A ceiling-mounted X-ray machine $\dagger$ and a computed radiography system $\ddagger$ were used to obtain the thoracic radiographs.

The body weight of the foals ranged from 45 to $65 \mathrm{~kg}$, but all radiographs were made at $80 \mathrm{kVp}$ and $5 \mathrm{~mA}$ at a $100 \mathrm{~cm}$ focus-film distance. Radiographs were made at peak inspiration with the foal in lateral recumbency with the forelimbs pulled cranially from over the lung field. After each exposure the radiograph was evaluated for adequacy of positioning, phase of respiration, and exposure so that poor-quality studies could be eliminated. Postprocessing of the images was based on a thorax algorithm. Deficient radiographs were discarded and corresponding images repeated.

To achieve an objective and comparable assessment, a scoring system was developed for radiographic evaluation. Three independent observers evaluated each radiograph and scored them individually. The general assessment of duration of clearance was followed by the evaluation of all four (craniodorsal-, cranioventral-, caudodorsal-, and caudoventral-) lung quadrants individually to characterize the pattern of clearance.

In the general assessment, the lung patterns were graded from 1 to 3 . Radiographs with marked pulmonary opacity were scored as 3, radiographs with less opacity but blurring of small vessels were scored as 2, and normal appearing thoracic radiographs were scored as 1 . The average score

\footnotetext{
*Flett Street Corporation, Gaithersburg, MD.

$\dagger$ Optimus, tube SRO 2550, Philips Medical Systems, Hamburg, Germany.

$\ddagger$ Easy Vision, Philips Medical Systems.
}

for the three observers was computed at each time point; complete fluid clearance was defined as the time as which the average reached score equaled 1 .

We compared left-to-right and right-to-left radiographs at each given time point. If the score for each view was the same, the paired images were given a mark of 0 and if the score for each view was different, the paired images were given a mark of 1 . To compare left vs. right lateral radiographs, a logistic mixed model using Penalized QuasiLikelihood was built. ${ }^{16}$ The explanatory variables were the interpreter and time and the foal identifier was a random factor to take into account the correlated measurements.

Finally, a slightly different, more sensitive, scoring system was used to grade the four lung quadrants individually. The interstitial-alveolar opacity in each quadrant was graded as normal, mild, moderate, or severe and assigned grades from 0 to 3 . The individual grading of the quadrants was performed up to $6 \mathrm{~h}$ and only on the left-to-right images.

To verify the interpretations, Kendall's coefficient of concordance $\left(W_{\mathrm{t}}\right)$ was calculated. ${ }^{17}$ The coefficient was determined only for the evaluations in the first $4 \mathrm{~h}$ because thereafter all images from all foals received a score 1 from all observers. Statistical analyses were performed using R 2.8.0. ${ }^{18}$

\section{Results}

Mares had a gestation length between 329 and 340 days and uncomplicated parturition.

All foals were physically normal. Some moist crackles were heard in the first $30 \mathrm{~min}$ in all foals, but after this time only normal respiratory sounds were heard. A grade III, systolic, left-sided heart murmur could be heard during the first $24-48 \mathrm{~h}$ in two foals. One foal stood within $30 \mathrm{~min}$ after birth, two within the first hour, and five between 60 and $120 \mathrm{~min}$. Until being able to stand, foals were usually in sternal recumbency and periods of prolonged lateral recumbency were not observed.

Arterial $\mathrm{pH}, p \mathrm{CO}_{2}$, and $p \mathrm{O}_{2}$ values improved in the first $3 \mathrm{~h}$ with mean $\mathrm{pH}$ increasing from $7.295(\mathrm{SD}=0.030)$ to $7.359(\mathrm{SD}=0.062)$, mean $p \mathrm{CO}_{2}$ decreasing from $49.6 \mathrm{mmHg}$ $(\mathrm{SD}=7.55)$ to $44 \mathrm{mmHg}(\mathrm{SD}=3.03)$, and mean $p \mathrm{O}_{2}$ increasing from $77 \mathrm{mmHg}(\mathrm{SD}=7.55)$ to $95 \mathrm{mmHg}(\mathrm{SD}=$ 12.98). After this initial period $\mathrm{pH}$ decreased slightly, $p \mathrm{CO}_{2}$ increased slightly, and $p \mathrm{O}_{2}$ fluctuated. No foal was eliminated because of any laboratory abnormality.

There was agreement among the interpreters both in the general evaluation $\left(W_{\mathrm{t}}=0.898, P<0.001\right)$ and in the individual quadrant evaluation $\left(W_{\mathrm{t}}=0.93-0.97, P<0.001\right)$. According to each interpreter, all foals had a clear lung field by the 6th hour after birth.

Although there was agreement between observers, the subjectivity of the radiographic evaluation process still has 


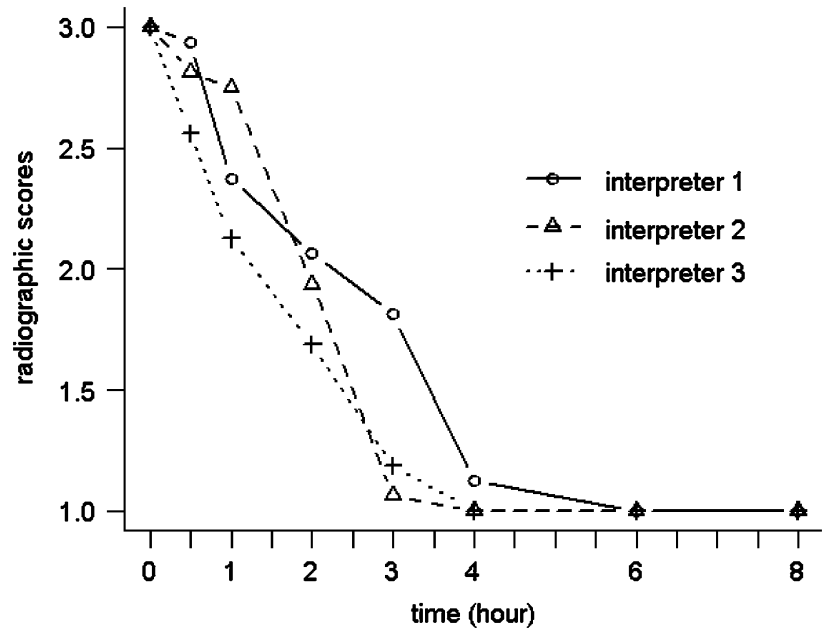

FIG. 1. Clearance of thoracic radiographic opacity. Average scores of the three independent interpreters as a function of time after birth. Note differences between interpreters at some evaluation times.

an influence on the results (Fig. 1). One observer evaluated one foal as still having vascular blurring at $4 \mathrm{~h}$ while the two other radiologists thought lung clearing occurred by $3-4 \mathrm{~h}$. When comparing left-to-right vs. right-to-left radiographs, scores were interpreter-dependent $(P=0.002)$. Clearing of the cranioventral and caudoventral lung field preceded that of the dorsal quadrants (Fig. 2).

\section{Discussion}

In human neonates there is rapid complete lung aeration. ${ }^{19,20}$ Previously, it was determined that normal foals had clear lungs within $12 \mathrm{~h}$ of birth but the kinetics of clearance were not assessed. ${ }^{21}$ In newborn lambs delivered

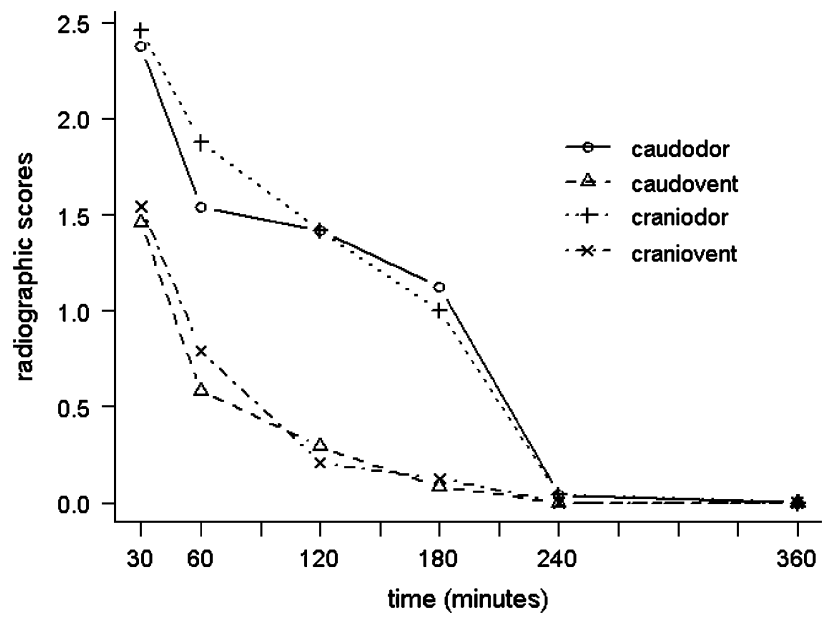

Fig. 2. Patterns of radiographic clearance in different lung quadrants: $\times$, cranioventral; + , craniodorsal; $\circ$, caudodorsal; $\Delta$, caudoventral. Fluid cleared most rapidly from ventral lung fields. at term by cesarean section, lung clearing occurred between 1 and $4 \mathrm{~h}$, with the cranial aspect of the lung clearing first. ${ }^{22}$

In rabbits, the critical role of the dynamics of lung aeration with regard to physiologic changes were clarified. ${ }^{1}$ Transpulmonary hydrostatic pressure generated by inspiration provided the predominant driving force for residual airway fluid clearance. Also, the degree of lung aeration at each time point was variable with some lungs being well aerated at $30 \mathrm{~s}$, while others were only partially aerated at $2 \mathrm{~h} .{ }^{1}$

Whether the pulmonary opacity seen in these neonatal foals represented fluid, atelectasis, aspirated cells, or an exudate was not determined. However, based on the normal adaptation period, we presumed the lungs were normal and that the opacity was due mainly to fetal lung fluid.

We followed the dynamics of postpartum clearance of equine pulmonary fluid from the 30th minute after birth until $72 \mathrm{~h}$ and concluded that clearing of the equine lung occurs within 3-6h of birth. Foals with respiratory distress syndrome may have abnormal pulmonary radiographic opacity beyond the normal fluid clearance time. ${ }^{3,7}$ Delayed resorption of pulmonary fluid leading to increased pulmonary radiographic opacity was observed on thoracic images of infants. ${ }^{23}$ In equine neonates, physiologic postpartum fluid absorption seems to take longer period than in humans. The primary mechanism of lung liquid reabsorption is the change in ion transport induced by catecholamines during labor. In humans the vast bulk of this fluid leaves the lung before normal term birth. ${ }^{24}$ Because humans have relatively prolonged labor compared with horses enabling more time for absorption, this might be the cause of the shorter radiographic lung clearance in infants. Fluid absorption time of this study was more similar to data from lambs. We did not acquire thoracic radiographs immediately after initiation of respiration, which would be of value to describe the kinetics of fluid resorption in more detail.

During the first hours after delivery, foals were in sternal recumbency. Considering the effect of gravity on fluid distribution, we suspected that fluid resorption would begin in the dorsocaudal region. To the contrary, fluid resprotion from the ventral quadrants preceded that of the dorsal quadrants (Fig. 3). This pattern can be the result of the distribution of amiloride sensitive $\mathrm{Na}^{+}$channels in the lung epithelium of the newborn. It is also possible that the thoracic wall is more flexible ventrally, where it expands relatively faster. Similarly in human infants, the air first fills the inferior lung fields, surrounded by the only part of the ribcage that expands. ${ }^{20}$ In rabbits the spatial pattern of lung aeration is influenced by the motion of the diaphragm and the nonuniform way the chest wall deforms during inspiration. ${ }^{1}$ There is no evidence for gravity-related movement of fluid, indicating that surface tension prevents significant movement of fluid between regions of the aerating lung. ${ }^{1}$ 


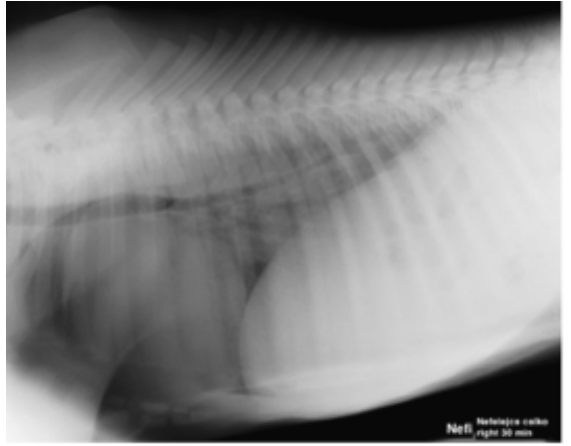

Foal A: 30 mins., Score 3

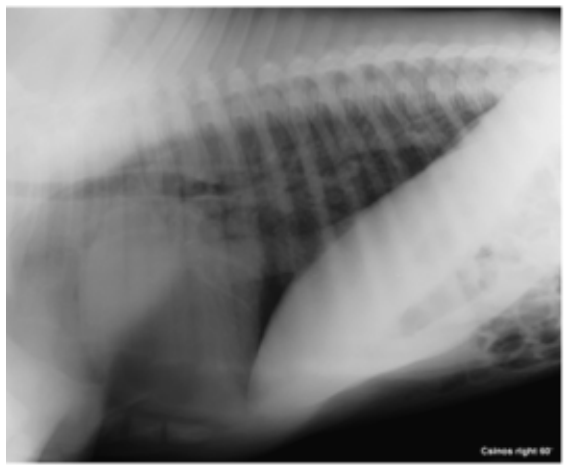

Foal B: 1 hour, Score 2

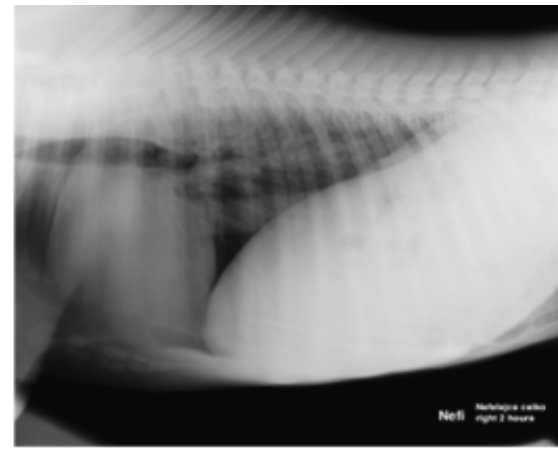

Foal A: 2 hours, Score 2

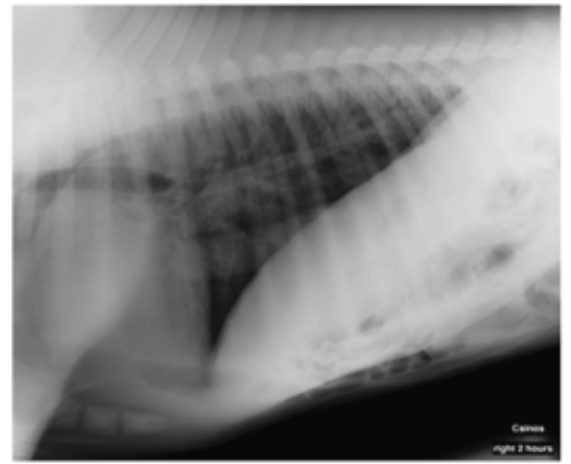

Foal B: 2 hours, Score 2

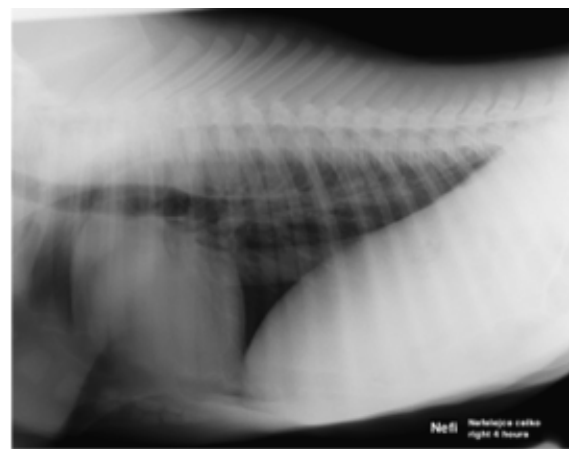

Foal A: 4 hours, Score 1

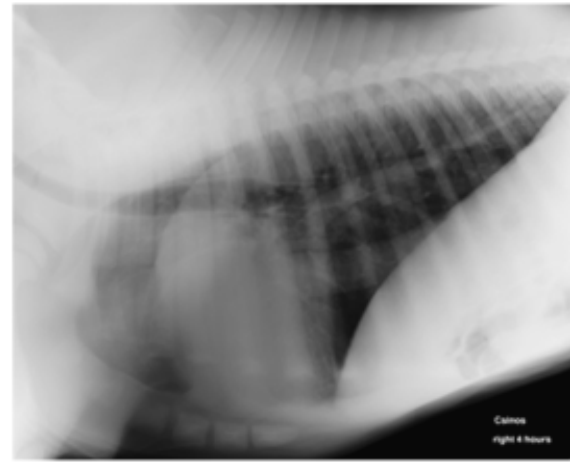

Foal B: 4 hours, Score 1

FIG. 3. Series of left-to-right lateral thoracic raiographs of two foals (A and B). Note the fluid absorption pattern and change in radiopacity. The clearing of the ventral quadrants preceded that of the dorsal quadrants.

The air/liquid interface moves toward the distal airways during inspiration because of transpulmonary pressure. Inspiratory activity and body position influences the process. ${ }^{1}$

In prolonged lateral recumbency, the dependent lung undergoes atelectasis. The nondependent lung is better aerated and characterized by better radiographic contrast, which is more conducive to detection of lung disease. ${ }^{7}$ For this reason, both left-to-right and right-to-left lateral radiographs were evaluated with respect to each other at each time point. Ventrodorsal projections would provide additional information on fluid lateralization, but these projections were not obtained because of the associated stress. We found significant differences between left-to-right and right-to-left lateral radiographs but lateral recumbency of the foal before radiography did not result in more pulmonary opacity on the dependent side, likely due to the short time foals spent in continuous lateral recumbency. In recumbent anesthetized horses, the maximum radiographic opacity of the dependent lung developed within 20 min of recumbency. ${ }^{25}$ The increased opacity often improved within minutes of standing. ${ }^{7}$ Regardless of the effect of recumbency, there were still different scores for left-to-right vs. right-to-left radiographic images in $5.7 \%$ of all evaluations. Apart from dependent atelectasis, other reasons for this difference could be distortion resulting from small changes in position of central beam or because radiographs were obtained at slightly different phases of respiration. The effect of body position was assessed in rabbits, where the dependent region of the lung aerated more slowly than nondependent regions, leading to a nonuniform pattern of lung aeration. ${ }^{1}$ This body position dependence is also more the result of restricted movements of the thoracic wall than of compression by mediastinal structures or to displacement of the diaphragm by abdominal contents.

In conclusion, $6 \mathrm{~h}$ after birth is the earliest time when normal foals reliably have clear lung fields on radiographs. Images at this time, and later, can be evaluated successfully and conclusions between physiologic and pathologic conditions drawn. Ventral lung cleared first, presumably because this region is bounded by the most flexible region of the thoracic wall. It is most likely that the free expansion of the thorax is important in lung aeration, which is more easily maintained in sternal recumbency or in a standing position.

\section{ACKNOWLEDGMENTS}

The authors would like to thank Remenyi Blanka, Lombay Bela, Rostas Tamas, and Kiss Zsuzsanna for their assistance in evaluating and interpreting neonatal radiographic images. 


\section{REFERENCES}

1. Hooper SB, Kitchen MJ, Wallace MJ, et al. Imaging lung aeration and lung liquid clearance at birth. FASEB J 2007;21:3329-3337.

2. Freeman L, Paradis MR. Evaluation of the effectiveness of equine neonatal care. Vet Med 1992;87:921-926.

3. Wilkins PA. Lower respiratory problem of the neonate. Vet Clin North Am Equine Pract 2003;19:19-33.

4. Koterba AM. Respiratory disease: approach to diagnosis. In: Koterba AM, Drummond WH, Kosch PC (eds): Equine clinical neonatology, 1st ed. Philadelphia: Lea \& Febiger, 1990;153-177.

5. Bedenice D, Heuwieser W, Solano M, Rand W, Paradis MR. Risk factors and prognostic variables for survival of foals with radiographic evidence of pulmonary disease. J Vet Intern Med 2003;17:868-875.

6. Bedenice D, Heuwieser W, Brawer R, Solano M, Rand W, Paradis MR. Clinical and prognostic significance of radiographic pattern, distribution, and severity of thoracic radiographic changes in neonatal foals. J Vet Intern Med 2003;17:876-886.

7. Lester GD, Lester NV. Abdominal and thoracic radiography in the neonate. Vet Clin North Am Equine Pract 2001;17:35-45.

8. Toal RL, Cudd T. Equine neonatal thoracic radiography: a radiographic-pathologic correlation. Proc Am Assoc Equine Pract 1986;32:117128.

9. Dickson KA, Maloney JE, Berger PJ. Decline in lung liquid volume before labor in fetal lambs. J Appl Physiol 1986;61:2266-2272.

10. Jain L, Douglas MD, Eaton C. Physiology of fetal lung fluid clearance and the effect of labour. Semin Perinatol 2006;30:34-43.

11. Chua BA, Perks AM. The pulmonary neuroendocrine system and drainage of the fetal lung: effects of serotonin. Gen Comp Endocrinol 1999;113:374-387.

12. Olver RE, Walters DV, Wilson SM. Developmental regulation of lung liquid transport. Annu Rev Physiol 2004;66:77-101.

13. Verkmann AS. Role of aquaporins in lung liquid physiology. Respir Physiol Neurobiol 2007;159:324-330.

14. Machay T. Cardiorespiratory adaptation of the infant: disturbances of adaptation (in Hungarian: Az újszülöttek kardioreszpiratórikus adaptá- ciója; adaptációs zavarok). Gyermekgyógyászati Továbbképzõ Szemle (translation of Pediatr Rev) 2004;9:211-216.

15. Bland RD, Hansen TN, Haberkern CM, et al. Lung fluid balance in lambs before and after birth. J Appl Physiol 1982;53:992-1004

16. Venables WN, Ripley BD. Modern applied statistics with S, 4th ed. New York: Springer, 2002

17. Kendall MG. Rank correlation method. London: Griffin and Company Ltd, 1948.

18. R Development Core Team. R: a language and environment for statistical computing. Vienna, Austria: R Foundation for Statistical Computing, 2007, ISBN 3-900051-07-0. Available at http://www.R-project. org (accessed October 28, 2008).

19. Yao AC, Lind J. Current concepts on respiratory and circulatory adaptation of the fetus and newborn. Eur J Obstet Gynecol Reprod Biol 1976;6:347-358

20. Fawcitt I, Lind J, Wegelius C. The first breath: a preliminary communication describing some methods of investigation of the first breath of a baby and the results obtained from them. Acta Pediatr 1960;49 (Suppl):5-17.

21. Lamb ChR, O'Callaghan WO, Paradis MR. Thoracic radiography in the neonatal foal: a preliminary report. Vet Radiol and Ultrasound 1990;31:11-16.

22. Fletcher BD, Sachs BF, Kotas RV. Radiologic demonstration of postnatal liquid in the lung of newborn lambs. Pediatrics 1970;46: $252-258$.

23. Kuhn JP, Fletcher BD, DeLemos RA. Roentgen findings in transient tachypnea of the newborn. Radiology 1969;92:751-757.

24. Alvaro RE, Rigatto H. Cardiorespiratory adjustments at birth. In: Avery GB, MacDonald MG, Seshia MM, Mullett MD (eds): Avery's neonatology: pathophysiology and management of the newborn, 6th ed. Portland: Lippincott Williams \& Wilkins, 2005;284-304.

25. McDonell WN, Hall LW. Radiographic evidence of impared pulmonary function in laterally recumbent anaesthetised horses. Equine Vet $\mathrm{J}$ 1979;11:24-32. 